\title{
A high-frequency phase feature for the measurement of magnetic permeability using eddy current sensor
}

\author{
Mingyang $\mathrm{Lu}^{1,{ }^{1,+}}$, Xiaobai Meng ${ }^{2,+}$, Ruochen Huang ${ }^{1}$, Liming $\mathrm{Chen}^{1}$, Anthony Peyton ${ }^{1}$, Wuliang Yin $^{1, *}$ \\ ${ }^{1}$ School of Electrical and Electronic Engineering, University of Manchester, Oxford Road, Manchester, M13 9PL, UK \\ ${ }^{2}$ Faculty of Art, Science and Technology, University of Northampton, Northampton, NN1 5PH, UK \\ + M. Lu and X. Meng contributed equally and share the first authorship. \\ *Corresponding author: mingyang.lu@manchester.ac.uk; wuliang.yin@manchester.ac.uk
}

\begin{abstract}
Electromagnetic sensing has been used for diverse applications of non-destructive testing, including the surface inspection, measurement of properties, object characterization. However, the measurement accuracy could be significantly influenced by the lift-off between sensors and samples. To address the issue caused by liftoffs, various strategies have been proposed for the permeability measurement of ferromagnetic steels, which mainly involves different sensor designs and signal features (e.g., the zero-crossing feature). In this paper, a single high-frequency scenario for the permeability retrieval is introduced. By combining the signal of two sensing pairs, the retrieval of magnetic permeability is less affected by the lift-off of sensors. Unlike the previous strategy on reducing the lift-off effect (directly taking the phase term out of the integration) using the Dodd-Deeds analytical method, the proposed method is based on a high-frequency linear feature of the phase term. Therefore, this method has the merit of high accuracy and fast processing for the permeability retrieval (a simplified version of DoddDeeds analytical formulas after the integration). Experimental measurement has been carried out on the impedance measurement of designed sensors interrogating ferromagnetic dual-phase steels. For sensor lift-offs of up to 10 $\mathrm{mm}$, the error of the permeability retrieval is controlled within $4 \%$ under the optimal frequency.
\end{abstract}

Index Terms - electromagnetic sensing, lift-off, eddy current, magnetic permeability, non-destructive testing.

\section{Introduction}

As one of the promising methods in the field of non-destructive testing (NDT), the electromagnetic (EM) sensing technique [1-9] has used to exploit the electromagnetic characteristics of steels, including the EM properties, surface inspection, B-H saturation, hysteresis of ferromagnetic materials [10-20]. Both the pulsed eddy current (PEC) $[9,10,12,18,20-23]$ and multi-frequency eddy current techniques [24-26] have been used to retrieve the permeability from the measured impedance. However, the lift-off of eddy current probes could significantly influence the measurement signal and thus the retrieval of magnetic permeabilities.

Novel sensor designs, post-processing techniques, and measurement manners have been proposed for reducing the permeability measurement error caused by the lift-off effect [18,20-24]. Giguère et al. have found a feature lift-off point of intersection (LOI) from the pulsed eddy current signal, which allows for an accurate evaluation of the ferromagnetic materials [20]. The LOI feature has been widely applied in the estimation of coating thickness, and measurement of ferromagnetic materials [21-23]. Tian et al. have proposed a four-point potential drop method in the form of multi-frequency spectra, which has its merit of simultaneously measuring both the electrical conductivity and magnetic permeability but restrained by its contact-sensing manner [24]. Besides, Tian and Sophian have used two references from air measurement and defect-free sample measurement for reducing the lift-off effect [18]. These methods apply to the evaluations of meta properties using PEC techniques.

Previously, both the iterative method [25], multi-frequency analysis - zero-crossing frequency feature (ZCF) [26], finite-element analysis (FEA) [27], conductivity invariance phenomenon (CIP) [28], and real-time embedded algorithm based on novel sensor design [29,30] have been proposed for the reconstruction of the ferromagnetic plate. From the iterative method [25], multiple parameters (including the conductivity, permeability, thickness, and lift-offs) are retrieved by analysing both the real and imaginary part of the impedance. The ZCF feature is proved sensitive to the test piece [26], where algorithms have been proposed to incorporate the ZCF feature for compensating the lift-off effect on the permeability retrieval. The FEA method [27] is based on a customised MATLAB scripted solver, which can further retrieve the phase fractions of alloys based on the predicted permeability. However, both the zero-crossing frequency feature, finite-element analysis, and iterative method are hampered by their long processing time, and need to recalibrate for different sensor setups. From the CIP feature [28], it is found that on an optimal sensor-sample lift-off, the measured impedance is barely affected by the 
electrical conductivities of tested steels. The CIP feature is only valid for the drive-pickup (where the transmitter and receiver are horizontally separated) sensor structure.

To reduce the lift-off effect on the retrieval of magnetic permeabilities, a high-frequency feature has been proposed in this paper. With a simplified Dodd-Deeds analytical method, the proposed scenario has hastened the computation (after the integration), which applies to the real-time retrieval of permeabilities or monitor of permeability inhomogeneities. Compared to the previous method on reducing the lift-off effect of permeability predictions [30], a similar triple-coil sensor setup but different retrieval strategies have been used. In the previous method, a real-time embedded algorithm is used, which is based on the slow change rate of the phase term $\phi$ with respect to $\alpha$ when using the Dodd-Deeds analytical approach. However, the change rate of the phase term is found still considerable for certain values of properties and frequencies. Thus, it needs to recalibrate for different frequencies and samples when using the previous method. Moreover, the retrieval in the previous method [30] is based on the phase of the impedance, which has a relatively lower sensitivities (compared to the impedance) to the variation of steel properties. In this paper, unlike the previous approach of assuming the slow change rate of the phase term $\phi$, a high-frequency feature (linear relationship) has been found between the ratio (imaginary part over real part) of the phase term $\phi$ and the integration variable $\alpha$. Thus, compared to the method reported in [30], the proposed method has a relatively high sensitivity (and accuracy, as the permeability is retrieved from the impedance instead of phase) does not need to recalibrate for different materials and frequencies. The Experimental measurement on ferromagnetic dual-phase alloys have been carried out for the verification of the proposed method.

\section{Methodology - high-frequency phase feature for the magnetic permeability measurement}

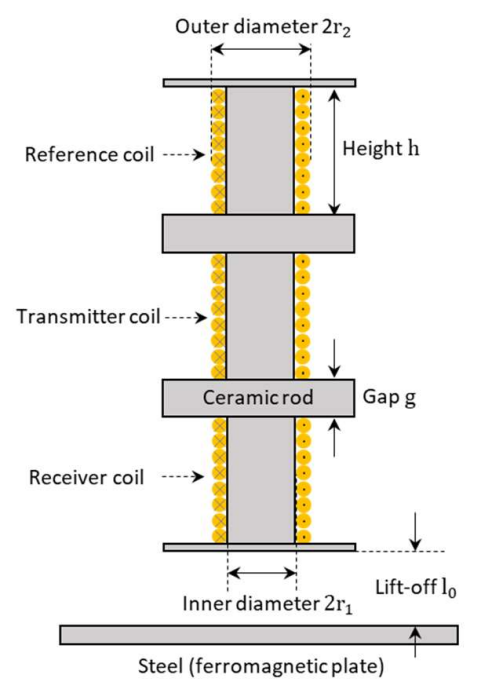

Fig. 1. Configuration of the sensor - three coils co-axially enwound

Both the A-V form finite element formulation [14] and the Dodd-Deeds method [31] have been widely utilised for the simulation of the electromagnetic field and sensor response. The finite element method (FEM) is a general approach for field computation in the media with arbitrary geometry and anisotropic properties. However, the solution of using FEM is significantly determined by the mesh resolution. A finely discretised mesh could result in hours of processing for the convergence. The Dodd-Deed method has been proposed for decades but is still the most dominant method for the interaction analysis between a circular coil and a conductive plate or co-axial cylindrical rod.

In Fig. 1, three coils, with a single transmitter coil and two sensing coils (one receiver coil and one reference coil), are equally wounded (same number of turns, and types of copper wires with insulating coatings) on slots (of the same radius) of a ceramic rod. The permeability retrieval is based on the impedance measurement from two sensing pairs (transmitter-receiver and transmitter-reference). Considering the sensitivities to the sample, the receiver is designed close to the test piece. The reference coil is symmetrically deployed with respect to the transmitter, to ensure that the permeability retrieval applies to a decent range of lift-offs. For circular coils above the ferromagnetic plate, as shown in Fig. 1, the impedance change (minus the background signal when the sensor is in the free space) test by transmitter-receiver and transmitter-reference sensing coils are shown in (1) and (2).

$$
\Delta \mathrm{Z}_{1}=\mathrm{j} \omega \overline{\mathrm{r} K} \int_{0}^{\infty} \frac{\mathrm{P}^{2}(\alpha)}{\alpha^{6}} \mathrm{~A}_{1}(\alpha) \phi(\alpha) \mathrm{d} \alpha
$$




$$
\Delta \mathrm{Z}_{2}=\mathrm{j} \omega \overline{\mathrm{r}} \mathrm{K} \int_{0}^{\infty} \frac{\mathrm{P}^{2}(\alpha)}{\alpha^{6}} \mathrm{~A}_{2}(\alpha) \phi(\alpha) \mathrm{d} \alpha
$$

In (1) (2), assume all the coils have the same number of turns $N$, coil height h,and inner and outer radii $r_{1}$ and $\mathrm{r}_{2}$. Then,

$$
\mathrm{K}=\frac{\pi \mathrm{N}^{2} \mu_{0}}{\mathrm{~h}^{2}\left(\mathrm{r}_{2}-\mathrm{r}_{1}\right)^{2}}
$$

In (3), $\mu_{0}$ is the vacuum permeability. $\overline{\mathrm{r}}$ is the mean value of the outer and inner radii for all the coils (both transmitter, receiver, and reference coils).

$$
\begin{gathered}
\overline{\mathrm{r}}=\frac{\mathrm{r}_{1}+\mathrm{r}_{2}}{2} \\
\mathrm{P}(\alpha)=\int_{\alpha \mathrm{r}_{1}}^{\alpha \mathrm{r}_{2}} \tau \mathrm{J}_{1}(\tau) \mathrm{d} \tau \\
\mathrm{A}_{1}(\alpha)=\mathrm{e}^{-\alpha\left(2 \mathrm{I}_{0}+\mathrm{g}+\mathrm{h}\right)}\left(\mathrm{e}^{-\alpha \mathrm{h}}-1\right)^{2} \\
\mathrm{~A}_{2}(\alpha)=\mathrm{e}^{-\alpha\left(2 \mathrm{I}_{0}+3 \mathrm{~g}+3 \mathrm{~h}\right)}\left(\mathrm{e}^{-\alpha \mathrm{h}}-1\right)^{2} \\
\phi(\alpha)=-\frac{\alpha_{1}-\mu_{1} \alpha}{\alpha_{1}+\mu_{1} \alpha} \\
\alpha_{1}=\sqrt{\alpha^{2}+\mathrm{j} \omega \sigma \mu_{1} \mu_{0}}
\end{gathered}
$$

Where, $\mathrm{J}_{1}$ denotes the first-order Bessel function of the first kind. $\tau$ and $\alpha$ are the variables for the integration. $\omega$ denotes the operation frequency. $\sigma$ is the electrical conductivity of the ferromagnetic sample. $\mu_{1}$ is the relative permeability of the ferromagnetic sample. $l_{0}$ denotes the sensor lift-off, which is the lower height of the receiver depicted in Fig. 1.

In the previous work, compared to the varying rate of $\frac{\mathrm{P}^{2}(\alpha)}{\alpha^{6}} \mathrm{~A}_{1}(\alpha)$ or $\frac{\mathrm{P}^{2}(\alpha)}{\alpha^{6}} \mathrm{~A}_{2}(\alpha), \phi(\alpha)$ was assumed to be almost immune to $\alpha$. Thus $\phi(\alpha)$ was regarded as a constant for varying $\alpha$ and taken out from the integration $[26,29,30]$. However, in general, the real part of the phase term $\phi(\alpha)$ is found to be almost linear to $\alpha$ under the high working frequency.

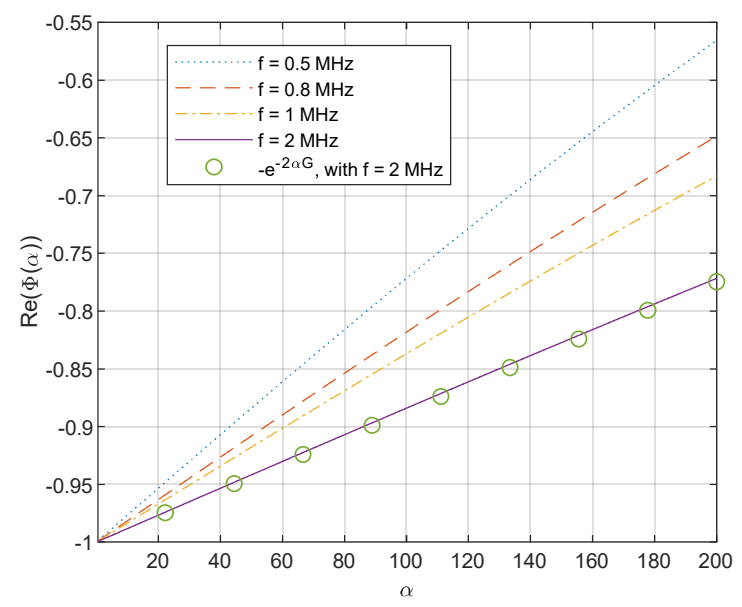

Fig. 2 Real part of $\phi(\alpha)$ versus $\alpha$ under high frequencies

In Fig. 2, the real part of $\phi(\alpha)$ vary slowly with $\alpha$ especially under high frequencies, which can be approximated as

$$
\operatorname{Re}(\phi(\alpha))=-\mathrm{e}^{-2 \alpha \mathrm{G}}
$$

$\mathrm{G}$ in (11) is a small value function and determined by $\omega, \sigma$, and $\mu_{1}$.

Therefore, under high working frequencies, the real part and imaginary part of the impedance for transmitterreceiver and transmitter-reference sensing coil - (1) and (2) are shown in the following equations.

$$
\begin{gathered}
\operatorname{Re}\left(\Delta \mathrm{Z}_{1}\right)=-\omega \overline{\mathrm{r} K} \int_{0}^{\infty} \frac{\mathrm{P}_{1}(\alpha)}{\alpha^{6}} \mathrm{e}^{-\alpha\left(2 \mathrm{l}_{0}+\mathrm{g}+\mathrm{h}\right)}\left(\mathrm{e}^{-\alpha \mathrm{h}}-1\right)^{2} \operatorname{Im}(\phi(\alpha)) \mathrm{d} \alpha \\
\operatorname{Im}\left(\Delta \mathrm{Z}_{1}\right)=-\omega \overline{\mathrm{r} K} \int_{0}^{\infty} \frac{\mathrm{P}_{1}(\alpha)}{\alpha^{6}} \mathrm{e}^{-\alpha\left(2\left(\mathrm{l}_{0}+\mathrm{G}\right)+\mathrm{g}+\mathrm{h}\right)}\left(\mathrm{e}^{-\alpha \mathrm{h}}-1\right)^{2} \operatorname{Re}(\phi(\alpha)) \mathrm{d} \alpha \\
\operatorname{Re}\left(\Delta \mathrm{Z}_{2}\right)=-\omega \overline{\mathrm{r} K} \int_{0}^{\infty} \frac{\mathrm{P}_{1}(\alpha)}{\alpha^{6}} \mathrm{e}^{-\alpha\left(2 \mathrm{l}_{0}+3 \mathrm{~g}+3 \mathrm{~h}\right)}\left(\mathrm{e}^{-\alpha \mathrm{h}}-1\right)^{2} \operatorname{Im}(\phi(\alpha)) \mathrm{d} \alpha \\
\operatorname{Im}\left(\Delta \mathrm{Z}_{2}\right)=-\omega \overline{\mathrm{r} K} \int_{0}^{\infty} \frac{\mathrm{P}_{1}(\alpha)}{\alpha^{6}} \mathrm{e}^{-\alpha\left(2\left(\mathrm{l}_{0}+\mathrm{G}\right)+3 \mathrm{~g}+3 \mathrm{~h}\right)}\left(\mathrm{e}^{-\alpha \mathrm{h}}-1\right)^{2} \operatorname{Re}(\phi(\alpha)) \mathrm{d} \alpha
\end{gathered}
$$


Moreover, as illustrated in Fig. 3, the term $\frac{\operatorname{Im}(\phi(\alpha))}{\operatorname{Re}(\phi(\alpha))}$ is found to be linear with the variable $\alpha$ under high frequencies.

$$
\operatorname{Im}(\phi(\alpha))=\operatorname{F} \alpha \operatorname{Re}(\phi(\alpha))
$$

$\mathrm{F}$ in (16) is the proportional function, which is also determined by $\omega, \sigma$, and $\mu_{1}$.

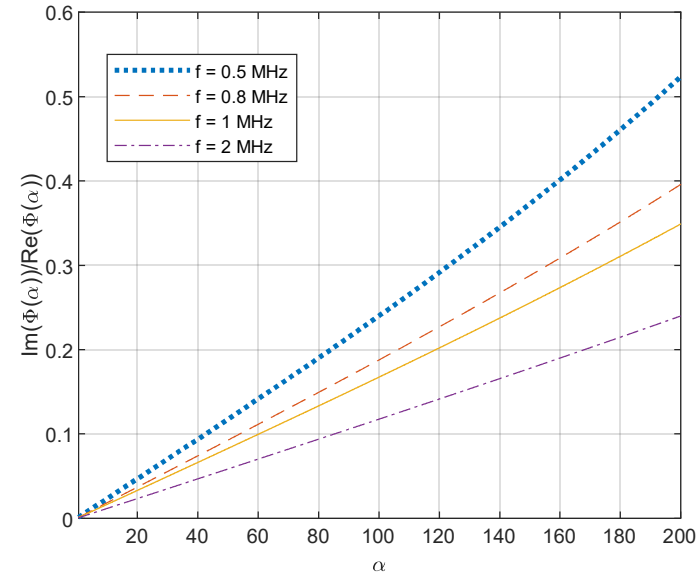

(a)

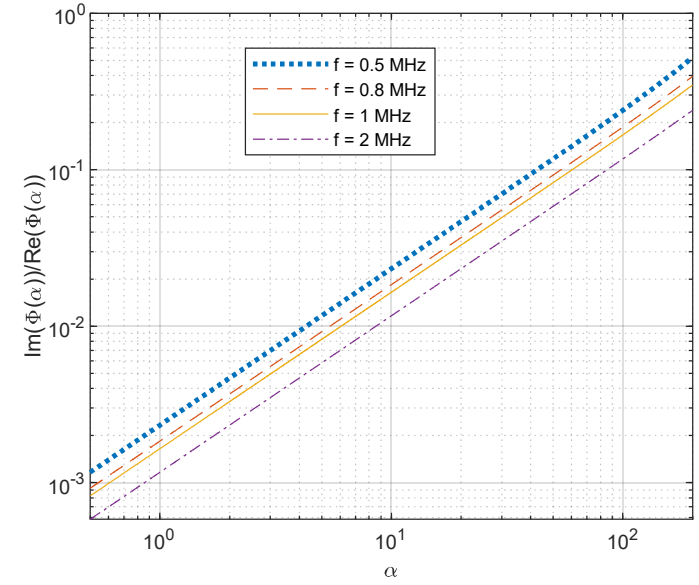

(b)

Fig. $3 \frac{\operatorname{Im}(\phi(\alpha))}{\operatorname{Re}((\alpha))}$ versus $\alpha$ under high frequencies a) linear plot b) $\log$-log plot

F can be derived by calculating its limit at $\alpha=0$, as shown in equation (17).

$$
\mathrm{F}=\lim _{\alpha \rightarrow 0} \frac{\operatorname{Im}(\phi(\alpha))}{\alpha \operatorname{Re}(\phi(\alpha))}=\sqrt{\frac{2 \mu_{1}}{\omega \sigma \mu_{0}}}
$$

Combine (16) and (17) with equations from (12) to (15), the real part and imaginary part of the impedance from transmitter-receiver and transmitter-reference sensing coils are shown in the following equations.

$$
\begin{gathered}
\operatorname{Re}\left(\Delta \mathrm{Z}_{1}\right)=\omega \mathrm{F} \overline{\mathrm{r} K} \int_{0}^{\infty} \frac{\mathrm{P}^{2}(\alpha)}{\alpha^{5}} \mathrm{e}^{-\alpha\left(2\left(\mathrm{l}_{0}+\mathrm{G}\right)+\mathrm{g}+\mathrm{h}\right)}\left(\mathrm{e}^{-\alpha \mathrm{h}}-1\right)^{2} \mathrm{~d} \alpha \\
\operatorname{Im}\left(\Delta \mathrm{Z}_{1}\right)=-\omega \overline{\mathrm{r} K} \int_{0}^{\infty} \frac{\mathrm{P}^{2}(\alpha)}{\alpha^{6}} \mathrm{e}^{-\alpha\left(2\left(\mathrm{l}_{0}+\mathrm{G}\right)+\mathrm{g}+\mathrm{h}\right)}\left(\mathrm{e}^{-\alpha \mathrm{h}}-1\right)^{2} \mathrm{~d} \alpha \\
\operatorname{Re}\left(\Delta \mathrm{Z}_{2}\right)=\omega \mathrm{F \overline {r } K} \int_{0}^{\infty} \frac{\mathrm{P}^{2}(\alpha)}{\alpha^{5}} \mathrm{e}^{-\alpha\left(2\left(\mathrm{l}_{0}+\mathrm{G}\right)+3 \mathrm{~g}+3 \mathrm{~h}\right)}\left(\mathrm{e}^{-\alpha \mathrm{h}}-1\right)^{2} \mathrm{~d} \alpha \\
\operatorname{Im}\left(\Delta \mathrm{Z}_{2}\right)=-\omega \overline{\mathrm{r} K} \int_{0}^{\infty} \frac{\mathrm{P}^{2}(\alpha)}{\alpha^{6}} \mathrm{e}^{-\alpha\left(2\left(\mathrm{l}_{0}+\mathrm{G}\right)+3 \mathrm{~g}+3 \mathrm{~h}\right)}\left(\mathrm{e}^{-\alpha \mathrm{h}}-1\right)^{2} \mathrm{~d} \alpha
\end{gathered}
$$

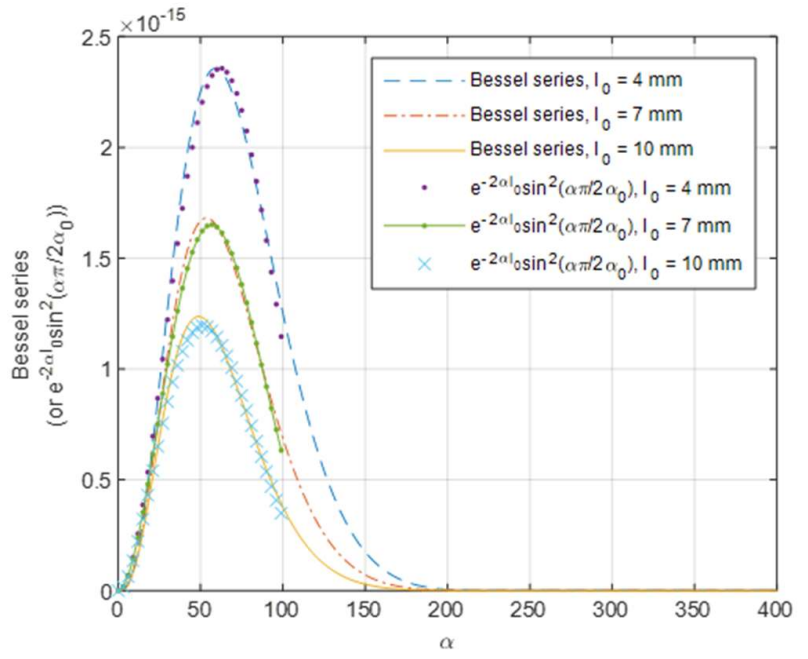

Fig. 4 The Bessel series $-\frac{\mathrm{P}^{2}(\alpha)}{\alpha^{5}} \mathrm{e}^{-\alpha\left(2 \mathrm{1}_{0}+\mathrm{g}+\mathrm{h}\right)}\left(\mathrm{e}^{-\alpha \mathrm{h}}-1\right)^{2}$ can be approximated as $\mathrm{e}^{-2 \alpha \mathrm{l}_{0}} \sin ^{2}\left(\frac{\alpha \pi}{2 \alpha_{0}}\right)$ 
As Fig. 4 depicts, the Bessel series in (18) and (20) $\frac{\mathrm{P}^{2}(\alpha)}{\alpha^{5}} \mathrm{e}^{-\alpha\left(2 \mathrm{l}_{0}+\mathrm{g}+\mathrm{h}\right)}\left(\mathrm{e}^{-\alpha \mathrm{h}}-1\right)^{2}$ can be estimated as the product between the lift-off attenuation factor $\mathrm{e}^{-2 \alpha \mathrm{l}_{0}}$ and the squared sinusoidal functions that peaks at $\alpha_{0}-$ $\mathrm{e}^{-2 \alpha \mathrm{l}_{0}} \sin ^{2}\left(\frac{\alpha \pi}{2 \alpha_{0}}\right)$.

$$
\begin{gathered}
\int_{0}^{\infty} \frac{\mathrm{P}^{2}(\alpha)}{\alpha^{5}} \mathrm{e}^{-\alpha\left(2\left(\mathrm{l}_{0}+\mathrm{G}\right)+\mathrm{g}+\mathrm{h}\right)}\left(\mathrm{e}^{-\alpha \mathrm{h}}-1\right)^{2} \mathrm{~d} \alpha=\mathrm{Z}_{m} \int_{0}^{2 \alpha_{0}} \mathrm{e}^{-2 \alpha\left(\mathrm{l}_{0}+\mathrm{G}\right)} \sin ^{2}\left(\frac{\alpha \pi}{2 \alpha_{0}}\right) \mathrm{d} \alpha \\
=\mathrm{Z}_{m} \frac{\pi^{2}\left(1-\mathrm{e}^{-4 \alpha_{0}\left(\mathrm{l}_{0}+\mathrm{G}\right)}\right)}{4\left(\mathrm{l}_{0}+\mathrm{G}\right)\left(4 \alpha_{0}{ }^{2}\left(\mathrm{l}_{0}+\mathrm{G}\right)^{2}+\pi^{2}\right)} \\
\int_{0}^{\infty} \frac{\mathrm{P}^{2}(\alpha)}{\alpha^{5}} \mathrm{e}^{-\alpha\left(2\left(\mathrm{l}_{0}+\mathrm{G}\right)+3 \mathrm{~g}+3 \mathrm{~h}\right)}\left(\mathrm{e}^{-\alpha \mathrm{h}}-1\right)^{2} \mathrm{~d} \alpha=\mathrm{Z}_{m} \int_{0}^{2 \alpha_{0}} \mathrm{e}^{-2 \alpha\left(\mathrm{l}_{0}+\mathrm{G}+\mathrm{g}+\mathrm{h}\right)} \sin ^{2}\left(\frac{\alpha \pi}{2 \alpha_{0}}\right) \mathrm{d} \alpha \\
=\mathrm{Z}_{m} \frac{\pi^{2}\left(1-\mathrm{e}^{-4 \alpha_{0}\left(\mathrm{l}_{0}+\mathrm{G}+\mathrm{g}+\mathrm{h}\right)}\right)}{4\left(\mathrm{l}_{0}+\mathrm{G}+\mathrm{g}+\mathrm{h}\right)\left(4 \alpha_{0}{ }^{2}\left(\mathrm{l}_{0}+\mathrm{G}+\mathrm{g}+\mathrm{h}\right)^{2}+\pi^{2}\right)}
\end{gathered}
$$

In (22) and (23), $\alpha_{0}{ }^{2}\left(\mathrm{l}_{0}+\mathrm{G}\right)^{2} \ll \pi^{2}, \alpha_{0}{ }^{2}\left(\mathrm{l}_{0}+\mathrm{G}+\mathrm{g}+\mathrm{h}\right)^{2} \ll \pi^{2}$. Therefore, (22) and (23) can be further approximated as

$$
\begin{gathered}
\int_{0}^{\infty} \frac{\mathrm{P}^{2}(\alpha)}{\alpha^{5}} \mathrm{e}^{-\alpha\left(2\left(\mathrm{l}_{0}+\mathrm{G}\right)+\mathrm{g}+\mathrm{h}\right)}\left(\mathrm{e}^{-\alpha \mathrm{h}}-1\right)^{2} \mathrm{~d} \alpha=\Delta \mathrm{Z}_{m} \frac{\left(1-\mathrm{e}^{-4 \alpha_{0}\left(\mathrm{l}_{0}+\mathrm{G}\right)}\right)}{4\left(\mathrm{l}_{0}+\mathrm{G}\right)} \\
\int_{0}^{\infty} \frac{\mathrm{P}^{2}(\alpha)}{\alpha^{5}} \mathrm{e}^{-\alpha\left(2\left(\mathrm{l}_{0}+\mathrm{G}\right)+3 \mathrm{~g}+3 \mathrm{~h}\right)}\left(\mathrm{e}^{-\alpha \mathrm{h}}-1\right)^{2} \mathrm{~d} \alpha=\Delta \mathrm{Z}_{m} \frac{\left(1-\mathrm{e}^{-4 \alpha_{0}\left(\mathrm{l}_{0}+\mathrm{G}+\mathrm{g}+\mathrm{h}\right)}\right)}{4\left(\mathrm{l}_{0}+\mathrm{G}+\mathrm{g}+\mathrm{h}\right)}
\end{gathered}
$$

In (24) and (25), $\alpha_{0}$ is named as the spatial frequency, which is a constant value for a specific sensor geometry. $\mathrm{Z}_{m}$ is used to normalise the squared sinusoidal functions and defined as

$$
\mathrm{Z}_{m}=\frac{\mathrm{P}^{2}\left(\alpha_{0}\right)}{\alpha_{0}{ }^{5}} \mathrm{e}^{-\alpha_{0}(\mathrm{~g}+\mathrm{h})}\left(\mathrm{e}^{-\alpha_{0} \mathrm{~h}}-1\right)^{2}
$$

Through mathematical manipulations (Appendix at the end), the permeability of the steel is retrieved by using the following equation.

$$
\mu_{1}=\frac{\mathrm{F} \omega \sigma \mu_{0}}{2}=\frac{2 \mathrm{R}_{1}^{2} \mathrm{R}_{2}^{2}(\mathrm{~g}+\mathrm{h})^{2} \sigma \mu_{0}}{\mathrm{Z}_{m}{ }^{2} \overline{\mathrm{r}}^{2} \mathrm{~K}^{2} \omega\left(\mathrm{R}_{1}-\mathrm{R}_{2}\right)^{2}}
$$

In (27), $\mathrm{R}_{1}=\operatorname{Re}\left(\Delta \mathrm{Z}_{1}\right), \mathrm{R}_{2}=\operatorname{Re}\left(\Delta \mathrm{Z}_{2}\right)$. Therefore, in (27), the magnetic permeability of the ferromagnetic plate can be reconstructed from the measured resistance from transmitter-receiver and transmitter-reference sensing coils.

\section{Sensor and experiment setup}

Experiments on the impedance measurement of the designed sensor deployed above the dual-phase (ferriteaustenite) alloy have been carried out for the test of the proposed method - (27).

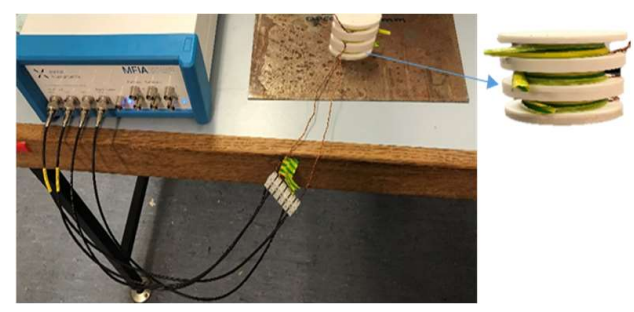

Fig. 5 Air-core sensor above the ferromagnetic sample is connected to the impedance analyser for the impedance measurement

As shown in Fig. 5, the sensor contains three coils - transmitter, receiver, and reference coils spirally wounded on the middle, bottom, and top buckets of the ceramic rod. The coils parameters including the number of turns, inner/outer diameters, height, and lift-offs are exhibited in Table 1. Three coils have the same turns and height. The lift-off is achieved by inserting the lift-off spacers between the sensor and sample, which ranges from $1 \mathrm{~mm}$ to $10 \mathrm{~mm}$ with $1 \mathrm{~mm}$ for each spacer. As listed in Table 2, the dual-phase (ferrite-austenite) alloys are DP 600 and DP 1000 with different phase fractions of the ferrite. The actual values of the relative magnetic permeability are 222 and 122 for DP 600 and DP 1000. The electrical conductivity of the alloy is measured from the four-terminal sensing method. The sensor is connected to the Zurich impedance analyser for the measurement of the multifrequency impedance spectra. The working frequency is from $1.0 \mathrm{kHz}$ to $2.0 \mathrm{MHz}$. It was found the signals have a poor Signal-to-Noise Ratio (SNR) for lower frequencies (particularly for frequencies lower than $1.0 \mathrm{kHz}$ ). Besides, the working frequency of the instrument ranges from $1 \mathrm{mHz}$ to $5 \mathrm{MHz}$, where the resonance effect (starts from approximately $7 \mathrm{MHz}$ ) barely happens. 
TABLE I

PARAMETERS OF THE DESIGNED SENSOR

Transmitter, Receiver 1, Receiver 2

\begin{tabular}{cc}
\hline & Transmitter, Receiver 1, Receiver 2 \\
\hline Gap $-\mathrm{g}(\mathrm{mm})$ & 4.5 \\
Turns $-\mathrm{N}$ & 10 \\
Height $-\mathrm{h}(\mathrm{mm})$ & 3.0 \\
Inner/Outer diameter $(\mathrm{mm})$ & $54.4 / 55.0$ \\
Lift-offs $-\mathrm{l}_{0}(\mathrm{~mm})$ & $1.0: 1.00: 10.0$ \\
\hline \hline
\end{tabular}

TABLE II

PROPERTIES OF THE FERROMAGNETIC PLATES

\begin{tabular}{ccc}
\hline \hline & DP 600 & DP 1000 \\
\hline $\begin{array}{c}\text { Thickness (mm) } \\
\text { Electrical conductivity } \\
\text { (MS/m) }\end{array}$ & 2.4 & 2.2 \\
$\begin{array}{c}\text { Relative magnetic } \\
\text { permeability }\end{array}$ & 2.13 & 3.80 \\
\hline \hline
\end{tabular}

\section{Results and discussions}

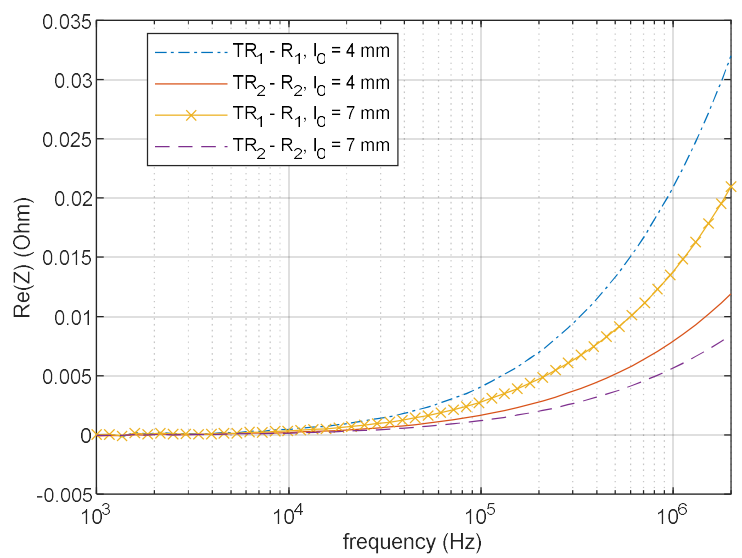

(a)

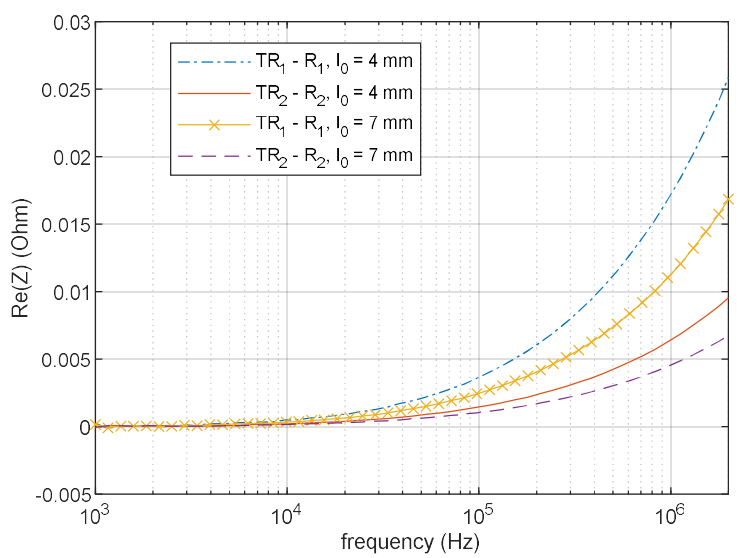

(b)

Fig. 6 Multi-frequency spectra of the electrical resistance (real part of impedance) under the sensor lift-off of $4 \mathrm{~mm}$ and $7 \mathrm{~mm}$ (a) DP 600 alloy (b) DP 1000 alloy

In Fig. 6, the electrical resistance under the working frequencies of from $1.0 \mathrm{kHz}$ to $2.0 \mathrm{MHz}$ has been illustrated. It can be seen that the resistance of the sensor above DP 600 alloy is slightly larger than that of DP 1000 alloy. In addition, the measured resistance is reduced for an increased sensor lift-off, which can be explained by the lift-off decay factor $\mathrm{e}^{-2 \alpha_{0}}$ in equation (18) and (20). Since the reference coil is much away from the sample compared to the receiver coil, less interaction exists between the sample and transmitter-reference sensing coil $\left(\mathrm{TR}_{2}\right)$. Consequently, the electrical resistance measured from transmitter-reference sensing coil $\left(\mathrm{TR}_{2}\right)$ is much smaller than that from transmitter-receiver sensing coil $\left(\mathrm{TR}_{1}\right)$, which can also be explicated by referring to the different term $\left(\mathrm{e}^{-\alpha(\mathrm{g}+\mathrm{h})}\right.$ and $\left.\mathrm{e}^{-3 \alpha(\mathrm{g}+\mathrm{h})}\right)$ between (20) and (18).

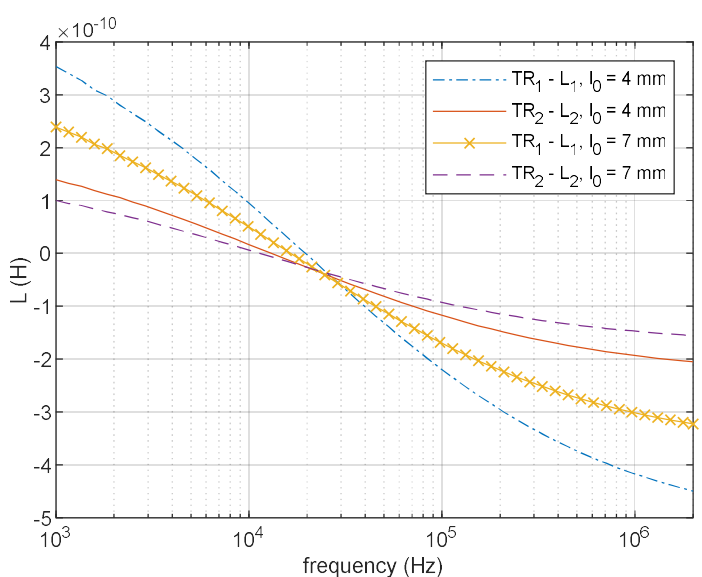

(a)

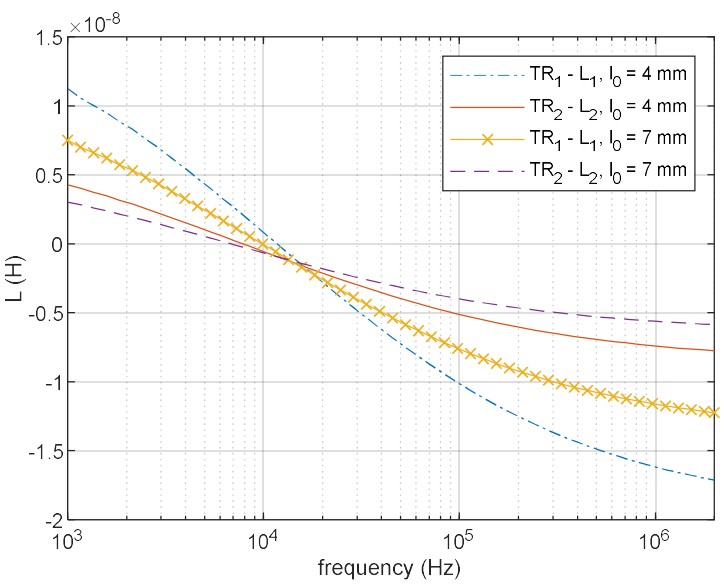

(b)

Fig. 7 Multi-frequency spectra of the inductance (imaginary part of impedance over $\omega$ ) under the sensor lift-off of $4 \mathrm{~mm}$ and $7 \mathrm{~mm}$ (a) DP 600 alloy (b) DP 1000 alloy

Fig. 7 demonstrates the inductance (the imaginary part of impedance or reactance over the angular frequency $\omega$ ) under the frequency range from $1.0 \mathrm{kHz}$ to $2.0 \mathrm{MHz}$. Similar to the trend of the multi-frequency 
resistance spectrum, the inductance is shown to be decreased on an increased sensor lift-off. Moreover, the measured inductance from transmitter-reference sensing coil $\left(\mathrm{TR}_{2}\right)$ is significantly smaller than that from transmitter-receiver sensing coil $\left(\mathrm{TR}_{1}\right)$ due to the less coupled effect between the sensing coil and sample. It can be observed that the inductance curve crossed zero at a certain frequency, which is named as the zero-crossing frequency $(\mathrm{ZCF})$ feature. In our previous work, the ZCF feature is linked to the magnetic permeability of the ferromagnetic sample based on the low varying rate of the phase term $\phi(\alpha)$. However, the phase term $\phi$ is proved can vary fast under a certain value of parameters (Fig. 2). Moreover, the ZCF method needs to be achieved under the sweeping frequency manner, which is time-consuming and need to recalibrate for real-time measurement when using different sensor setups.

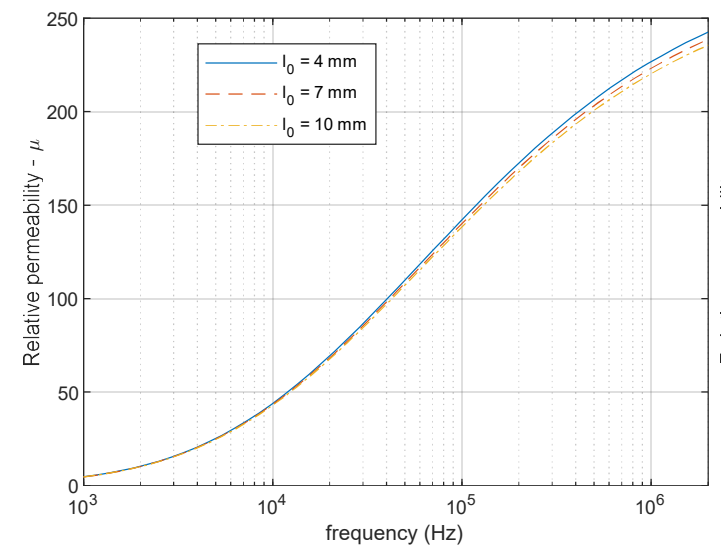

(a)

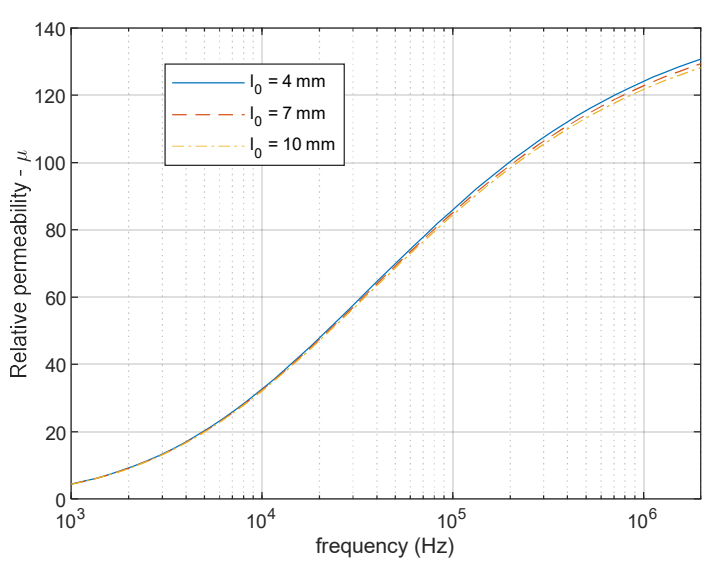

(b)

Fig. 8 Reconstructed relative magnetic permeability under different working frequencies with the sensor lift-off of $4 \mathrm{~mm}, 7 \mathrm{~mm}$, and $10 \mathrm{~mm}$ (a) DP 600 alloy (b) DP 1000 alloy

Fig. 8 depicts the reconstructed relative magnetic permeability of DP 600 and DP 1000 alloy under different working frequencies. The permeability is derived from the measured electrical resistance and the proposed algorithm (27). It can be seen that an increase in lift-off will result in a slightly reduced permeability value. Since the proposed method is based on the high-frequency phase feature (Fig. 2 and Fig. 3), the reconstructed permeability is significantly lower than the expected/actual permeability. From Fig. 8 (a) and (b), it can be found the optimal frequency for the reconstruction is around $1.0 \mathrm{MHz}$ for both DP 600 and DP 1000 alloy.

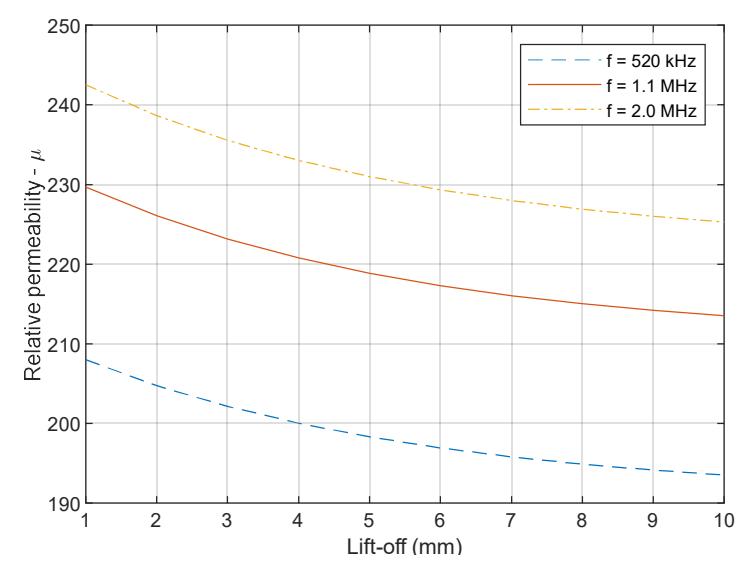

(a)

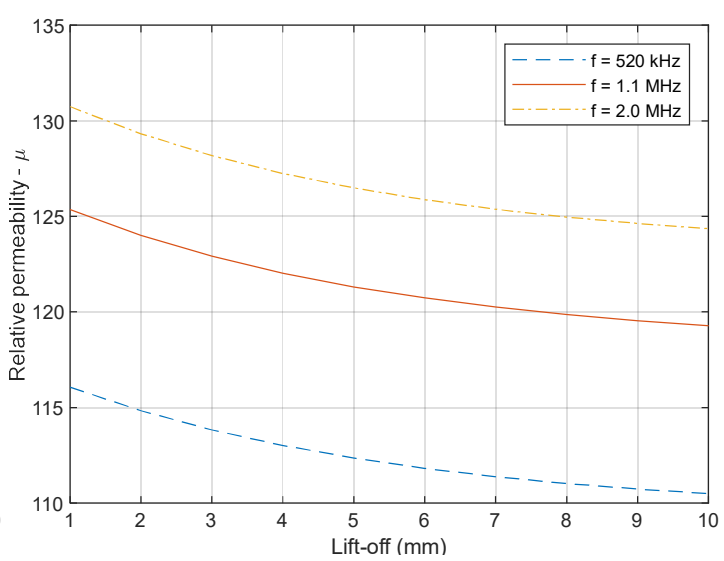

(b)

Fig. 9 Retrieved relative magnetic permeability using the proposed method under different working frequencies (520 kHz, $1.1 \mathrm{MHz}$, and 2.0 $\mathrm{MHz}$ ) with the sensor lift-off from $1 \mathrm{~mm}$ to $10 \mathrm{~mm}$ (a) DP 600 alloy (b) DP 1000 alloy

As the reconstructed magnetic permeability is more precious under high frequency - around $1 \mathrm{MHz}$, reconstruction results from three working frequencies $(520 \mathrm{kHz}, 1.1 \mathrm{MHz}$, and $2.0 \mathrm{MHz})$ have been extracted for the illumination of the lift-off effect. It can be seen that an increased lift-off will lead to a slightly reduced but gradually stable value. Comparing the three curves for both steel alloys, it is found that the optimal frequency for a high-accuracy reconstruction with a small range of lift-off (less than $10 \mathrm{~mm}$ ) is around $1.1 \mathrm{MHz}$. Under the optimal frequency $-1.1 \mathrm{MHz}$, the error of permeability retrieval is controlled within $4 \%$. Further increased lift- 
off will result in a distorted value due to the resolution of the first-order Padé approximation in (27) and (28). The optimal frequency for the permeability retrieval is sensor-dependent. For the sensor size listed in Table 1, the optimal frequency is around 1.1 MHz. In practical measurements of different sensor dimensions, it is suggested to use a benchmark sample with nominal property to find the optimal frequency (or optimal frequency range) for the permeability retrieval method.

\section{Conclusions}

In this paper, a high-frequency phase feature has been found in the phase term $\phi$ of the Dodd-Deed analytical formulation. Unlike the previous technique of directly taking the phase term out of the integration, both the real part and imaginary part of the phase term have been approximated by combined linear and exponential functions. The eddy current sensor contains three coils, with the transmitter, receiver, and reference coil wounded on the middle, bottom, and top bucket of the ceramic rod. By combining the measured electrical resistance from both transmitter-receiver and transmitter-reference coils, the relative permeability of the ferromagnetic plate can be reconstructed. From the carried-out experiments on the dual-phase alloy, the deviation on the permeability retrieval using the proposed method is within $4 \%$ for lift-offs of up to $10 \mathrm{~mm}$. Further increased sensor lift-off will lead to distortion due to the Padé approximation utilised in the proposed algorithm. The designed air-core sensor can only be used for the initial permeability measurement of the ferromagnetic specimen due to its weak induced magnetic field. An air-core sensor with a thicker wire could be used for the B-H saturation measurement of the ferromagnetic sample. As the skin depth of the eddy current is much smaller than the thickness of sample plates under the optimal frequency $(1.1 \mathrm{MHz})$, further increased thickness will not affect the accuracy of the permeability retrieval. Since the proposed method is under the relatively small magnetic field generated from the excitation current, the magnetization or the hysteresis (saturation) effect is not encountered. For the measurement of some ferromagnetic samples with higher permeability (e.g., electrical steel, which could have relative permeabilities of over 1000), the sample may be easily magnetised under a small magnetic field. Thus, in the future, more experiments will be carried out for the analysis of hysteresis effects on the permeability retrieval.

\section{Acknowledgments}

This work was supported by [UK Engineering and Physical Sciences Research Council (EPSRC)] [grant number: EP/P027237/1] [title: Real-time In-line Microstructural Engineering (RIME)].

Author Contributions: (Methodology, manuscript drafting) M. Lu and X. Meng; (conceptualization, manuscript revision) M. Lu, X. Meng; (experiment data curation, manuscript review) M. Lu, R. Huang, L. Chen; (Supervision) W. Yin, A. Peyton, M. Lu. All authors have read and agreed to the published version of the manuscript.

\section{Appendix}

For a small sensor lift-off of less than $10 \mathrm{~mm}$, according to the Padé approximation, $\mathrm{e}^{-4 \alpha_{0}\left(\mathrm{l}_{0}+\mathrm{G}\right)}$ and $\mathrm{e}^{-4 \alpha_{0}\left(\mathrm{l}_{0}+\mathrm{G}+\mathrm{g}+\mathrm{h}\right)}$ in $(24)$ and $(25)$ can be estimated as

$$
\begin{gathered}
\mathrm{e}^{-4 \alpha_{0}\left(\mathrm{l}_{0}+\mathrm{G}\right)}=-\frac{4 \alpha_{0}\left(\mathrm{l}_{0}+\mathrm{G}\right)-2}{4 \alpha_{0}\left(\mathrm{l}_{0}+\mathrm{G}\right)+2} \\
\mathrm{e}^{-4 \alpha_{0}\left(\mathrm{l}_{0}+\mathrm{G}+\mathrm{g}+\mathrm{h}\right)}=-\frac{4 \alpha_{0}\left(\mathrm{l}_{0}+\mathrm{G}+\mathrm{g}+\mathrm{h}\right)-2}{4 \alpha_{0}\left(\mathrm{l}_{0}+\mathrm{G}+\mathrm{g}+\mathrm{h}\right)+2}
\end{gathered}
$$

Substitute (28) and (29) into (24) and (25),

$$
\begin{gathered}
\int_{0}^{\infty} \frac{P^{2}(\alpha)}{\alpha^{5}} \mathrm{e}^{-\alpha\left(2\left(\mathrm{l}_{0}+\mathrm{G}\right)+\mathrm{g}+\mathrm{h}\right)}\left(\mathrm{e}^{-\alpha \mathrm{h}}-1\right)^{2} \mathrm{~d} \alpha=\mathrm{Z}_{m} \frac{\alpha_{0}}{2 \alpha_{0}\left(\mathrm{l}_{0}+\mathrm{G}\right)+1} \\
\int_{0}^{\infty} \frac{\mathrm{P}^{2}(\alpha)}{\alpha^{5}} \mathrm{e}^{-\alpha\left(2\left(\mathrm{l}_{0}+\mathrm{G}\right)+3 \mathrm{~g}+3 \mathrm{~h}\right)}\left(\mathrm{e}^{-\alpha \mathrm{h}}-1\right)^{2} \mathrm{~d} \alpha=\mathrm{Z}_{m} \frac{\alpha_{0}}{2 \alpha_{0}\left(\mathrm{l}_{0}+\mathrm{G}+\mathrm{g}+\mathrm{h}\right)+1}
\end{gathered}
$$

Combine (30) and (31) with (18) and (20),

$$
\begin{gathered}
\operatorname{Re}\left(\Delta \mathrm{Z}_{1}\right)=\mathrm{Z}_{m} \frac{\alpha_{0} \omega \mathrm{Fr} \mathrm{K}}{2 \alpha_{0}\left(\mathrm{l}_{0}+\mathrm{G}\right)+1} \\
\operatorname{Re}\left(\Delta \mathrm{Z}_{2}\right)=\mathrm{Z}_{m} \frac{\alpha_{0} \omega \mathrm{FrK}}{2 \alpha_{0}\left(\mathrm{l}_{0}+\mathrm{G}+\mathrm{g}+\mathrm{h}\right)+1}
\end{gathered}
$$

Let $\mathrm{R}_{1}=\operatorname{Re}\left(\Delta \mathrm{Z}_{1}\right), \mathrm{R}_{2}=\operatorname{Re}\left(\Delta \mathrm{Z}_{2}\right)$. The solution of $\left(\mathrm{l}_{0}+\mathrm{G}\right)$ and $\mathrm{F}$ can be derived. 


$$
\begin{aligned}
\left(l_{0}+\mathrm{G}\right) & =\frac{\mathrm{R}_{2}-\mathrm{R}_{1}+2 \mathrm{R}_{2} \alpha_{0}(\mathrm{~g}+\mathrm{h})}{2 \alpha_{0}\left(\mathrm{R}_{1}-\mathrm{R}_{2}\right)} \\
\mathrm{F} & =\frac{2 \mathrm{R}_{1} \mathrm{R}_{2}(\mathrm{~g}+\mathrm{h})}{\mathrm{Z}_{m} \overline{\mathrm{r}} \mathrm{K} \omega\left(\mathrm{R}_{1}-\mathrm{R}_{2}\right)}
\end{aligned}
$$

Finally, the relative permeability of the ferromagnetic plate can be obtained by substituting (35) into (17).

\section{References}

$$
\mu_{1}=\frac{\mathrm{F} \omega \sigma \mu_{0}}{2}=\frac{2 \mathrm{R}_{1}{ }^{2} \mathrm{R}_{2}{ }^{2}(\mathrm{~g}+\mathrm{h})^{2} \sigma \mu_{0}}{\mathrm{Z}_{m}{ }^{2} \overline{\mathrm{r}}^{2} \mathrm{~K}^{2} \omega\left(\mathrm{R}_{1}-\mathrm{R}_{2}\right)^{2}}
$$

1. B. Liu, P. Huang, X. Zeng, Z. Li, "Hidden defect recognition based on the improved ensemble empirical decomposition method and pulsed eddy current testing." NDT \& E International, vol. 86, pp. 175-185, 2017.

2. J. C. Moulder, E. Uzal, J. H. Rose, "Thickness and conductivity of metallic layers from eddy current measurements." Review of Scientific Instruments, vol. 63, no. 6, 1992.

3. T. Theodoulidis, E. E. Kriezis, "Eddy current canonical problems (with applications to nondestructive evaluation)." Tech Sci. Press, Henderson, NV, USA, Sci. Rep. 0-9717880-1-4, 2006.

4. S. Giguere, S. J. Dubois, "Pulsed eddy current: finding corrosion independently of transducer lift-off." AIP Conference Proceedings, vol. 509, pp. 449-456, 2000.

5. X. Chen, Y. Lei, "Electrical conductivity measurement of ferromagnetic metallic materials using pulsed eddy current method." NDT \& E International, vol. 75, pp. 33-38, 2015.

6. G. Yang, G. Dib, L. Udpa, A. Tamburrino, S. S. Udpa, "Rotating Field EC-GMR Sensor for Crack Detection at Fastener Site in Layered Structures." IEEE Sensors Journal, vol. 15, pp. 463-470, 2015.

7. W. Li, X. Yuan, G. Chen, J. Ge, X. Yin, K. Li, "High sensitivity rotating alternating current field measurement for arbitrary-angle underwater cracks." NDT \& E International, vol. 79, pp. 123-131, 2016.

8. C. Mandache, J. Lefebvre, "Transient and harmonic eddy currents: Lift-off point of intersection." NDT \& E International, vol. 39, pp. $57-60,2006$

9. D. Vasic, V. Bilas, D. Ambrus, "Pulsed eddy-current nondestructive testing of ferromagnetic tubes." IEEE Transactions on Instrumentation and Measurement, vol. 53, pp. 1289-1294, 2004.

10. I. Z. Abidin, C. Mandache, G. Y. Tian, M. Morozov, "Pulsed eddy current testing with variable duty cycle on rivet joints." NDT \& E International, vol. 42, pp. 599-605, 2009.

11. J.R.S. Avila, M. Lu, et al., "Accurate measurements of plate thickness with variable lift-off using a combined inductive and capacitive sensor." NDT \& E International, vol. 110, pp. 102202, 2020.

12. Y. He, G. Tian, H. Zhang, M. Alamin, A. Simm, P. Jackson, "Steel Corrosion Characterization Using Pulsed Eddy Current Systems." IEEE Sensors Journal, vol. 12, pp. 2113-2120, 2012.

13. M. Lu, X. Meng, W. Yin, Z. Qu, F. Wu, J. Tang, et al., "Thickness measurement of non-magnetic steel plates using a novel planar triple-coil sensor." NDT \& E International, vol. 107, 2019.

14. M. Lu, et al., "Acceleration of frequency sweeping in eddy-current computation." IEEE Transactions on Magnetics, vol. 53, pp. 18, 2017.

15. G. Tytko, L. Dziczkowski, "E-Cored Coil With a Circular Air Gap Inside the Core Column Used in Eddy Current Testing." IEEE Transactions on Magnetics, vol. 51, pp. 1-4, Sept. 2015.

16. R. Huang, M. Lu, A. Peyton, W. Yin, "Thickness measurement of metallic plates with finite planar dimension using eddy current method." IEEE Transactions on Instrumentation and Measurement, vol. 69, 2020.

17. M. Lu, L. Yin, A. J. Peyton, W. Yin, "A novel compensation algorithm for thickness measurement immune to lift-off variations using eddy current method." IEEE Transactions on Instrumentation and Measurement, vol. 65, pp. 2773-2779, 2016.

18. G. Y. Tian, A. Sophian, "Reduction of lift-off effects for pulsed eddy current NDT." NDT \& E International, vol. 38, pp. 319-324, 2005.

19. L. Wei, C. Guoming, Y. Xiaokang, Z. Chuanrong, L. Tao, "Analysis of the lift-off effect of a U-shaped ACFM system.” NDT \& E International, vol. 53, pp. 31-35, 2013.

20. S. Giguere, B. A. Lepine, J. M. S. Dubois, "Pulsed eddy current technology: Characterizing material loss with gap and lift-off variations." Journal of Research in Nondestructive Evaluation, vol. 13, pp. 119-129, 2001.

21. Y. Wang, M. Fan, B. Cao, B. Ye, D. Wen, "Measurement of coating thickness using lift-off point of intersection features from pulsed eddy current signals." NDT \& E International, vol. 116, pp. 102333, 2020.

22. C.S. Angani, et al., "Lift-off point of intersection feature in transient eddy-current oscillations method to detect thickness variation in stainless steel." IEEE Transactions on Magnetics, vol. 52, pp. 1-8, 2016.

23. D. Wen, M. Fan, B. Cao, B. Ye, G. Tian, "Extraction of LOI Features from Spectral Pulsed Eddy Current Signals for Evaluation of Ferromagnetic Samples." IEEE Sensors Journal, vol. 19, pp. 189-195, 2019.

24. Y. Tian, "Electrical conductivity and magnetic permeability measurement of case hardened steels." AIP Conference Proceedings, vol. 1650, pp. 462-469, 2015.

25. M. Lu, et al., "Determination of the magnetic permeability, electrical conductivity, and thickness of ferrite metallic plates using a multi-frequency electromagnetic sensing system." IEEE Transactions on Industrial Informatics, vol. 15, pp. 4111-4119, 2019.

26. M. Lu, W. Zhu, L. Yin, A. J. Peyton, W. Yin, Z. Qu, "Reducing the lift-off effect on permeability measurement for magnetic plates from multifrequency induction data." IEEE Transactions on Instrumentation and Measurement, vol. 67, pp. 167-174, 2018.

27. W. Zhou, M. Lu, Z. Chen, L. Zhou, L. Yin, Q. Zhao, A. Peyton, Y. Li, W. Yin. "Three-Dimensional Electromagnetic Mixing Models for Dual-Phase Steel Microstructures.” Applied Sciences, vol. 8, pp. 529, 2018.

28. M. Lu, H. Xu, W. Zhu, L. Yin, et al., "Conductivity Lift-off Invariance and measurement of permeability for ferrite metallic plates." NDT \& E International, vol. 95, pp. 36-44, 2018.

29. M. Lu, et al., "Measurement of ferromagnetic slabs permeability based on a novel planar triple-coil sensor." IEEE Sensors Journal, vol. 20, pp. 2904-2910, 2020.

30. M. Lu, R. Huang, W. Yin, Q. Zhao, A. Peyton, "Measurement of permeability for ferrous metallic plates using a novel lift-off compensation technique on phase signature.” IEEE Sensors Journal, vol. 19, pp. 7440-7446, 2019. 
31. C. V. Dodd, W. E. Deeds, "Analytical solutions to eddy-current probe-coil problems.” Journal of applied physics, vol. 39, pp. 2829-2838, 1968.

32. R. Huang, M. Lu, A. Peyton, and W. Yin, "Thickness measurement of metallic plates with finite planar dimension using eddy current method," IEEE Transactions on Instrumentation and Measurement, early access, 2020. Doi:10.1109/TIM.2020.2987413.

33. M. Lu, et al. "Acceleration of frequency sweeping in eddy-current computation," IEEE Transactions on Magnetics, vol. 53, pp. 1$8,2017$.

34. M. Lu, H. Xu, W. Zhu, L. Yin et al. "Conductivity Lift-off Invariance and measurement of permeability for ferrite metallic plates," NDT \& E International, vol. 95, pp. 36-44, Apr. 2018.

35. W. Yin et al. "Permeability invariance phenomenon and measurement of electrical conductivity for ferrite metallic plates," InsightNon-Destructive Testing and Condition Monitoring, vol. 61, pp. 472-479, 2019.

36. M. Lu, W. Zhu, L. Yin, A. J. Peyton, W. Yin, and Z. Qu, "Reducing the lift-off effect on permeability measurement for magnetic plates from multifrequency induction data," IEEE Transactions on Instrumentation and Measurement, vol. 67, no. 1, pp. 167-174, Jan. 2018

37. M. Lu, L. Yin, A. J. Peyton and W. Yin, "A novel compensation algorithm for thickness measurement immune to lift-off variations using eddy current method," IEEE Transactions on Instrumentation and Measurement, vol. 65, no. 12, pp. 2773-2779, Dec. 2016.

38. M. Lu, R. Huang, W. Yin, Q. Zhao, and A. Peyton, "Measurement of permeability for ferrous metallic plates using a novel lift-off compensation technique on phase signature," IEEE Sensors Journal, vol. 19, no. 17, pp. 7440-7446, 1 Sept.1, 2019.

39. M. Lu et al. "Determining the magnetic permeability of ferrite steel strip by a custom inversion method," Proc. 12th ECNDT, pp. $1-8,2018$.

40. M. Lu, et al. "Determination of the magnetic permeability, electrical conductivity, and thickness of ferrite metallic plates using a multi-frequency electromagnetic sensing system," IEEE Transactions on Industrial Informatics, vol. 15, pp. 4111-4119, 2019.

41. J.R.S. Avila, M. Lu et al. "Accurate measurements of plate thickness with variable lift-off using a combined inductive and capacitive sensor,” NDT \& E International, vol. 110, pp. 102202, 2020.

42. M. Lu, R. Huang, W. Yin, Q. Zhao, and A. Peyton, "Measurement of permeability for ferrous metallic plates using a novel lift-off compensation technique on phase signature," IEEE Sensors Journal, vol. 19, no. 17, pp. 7440-7446, 1 Sept.1, 2019.

43. M. Lu, X. Meng, W. Yin, Z. Qu, F. Wu, J. Tang, et al., "Thickness measurement of non-magnetic steel plates using a novel planar triple-coil sensor," NDT \& E International, vol. 107, 2019.

44. M. Lu et al. "Measurement of ferromagnetic slabs permeability based on a novel planar triple-coil sensor," IEEE Sensors J., vol. 20, no. 6, pp. 2904-2910, 2020.

45. M. Lu, et al, "Determination of surface crack orientation based on thin-skin regime using triple-coil drive-pickup eddy-current sensor," IEEE Transactions on Instrumentation and Measurement, vol. 70, 2020.

46. J.R.S. Avila, M. Lu et al. "Accurate measurements of plate thickness with variable lift-off using a combined inductive and capacitive sensor," NDT \& E International, vol. 110, pp. 102202, 2020.

47. M. Lu, L. Yin, A. J. Peyton and W. Yin, "A novel compensation algorithm for thickness measurement immune to lift-off variations using eddy current method," IEEE Transactions on Instrumentation and Measurement, vol. 65, no. 12, pp. 2773-2779, Dec. 2016.

48. M. Lu, X. Meng, W. Yin, Z. Qu, F. Wu, J. Tang, et al., "Thickness measurement of non-magnetic steel plates using a novel planar triple-coil sensor," NDT \& E International, vol. 107, 2019.

49. R. Huang, M. Lu, A. Peyton, and W. Yin, "Thickness measurement of metallic plates with finite planar dimension using eddy current method," IEEE Transactions on Instrumentation and Measurement, early access, 2020. Doi:10.1109/TIM.2020.2987413.

50. M. Lu et al. "Measurement of ferromagnetic slabs permeability based on a novel planar triple-coil sensor," IEEE Sensors J., vol. 20, no. 6, pp. 2904-2910, 2020.

51. M. Lu, W. Zhu, L. Yin, A. J. Peyton, W. Yin, and Z. Qu, "Reducing the lift-off effect on permeability measurement for magnetic plates from multifrequency induction data," IEEE Transactions on Instrumentation and Measurement, vol. 67, no. 1, pp. 167-174, Jan. 2018.

52. R. Huang, M. Lu et al, "Measurement of the radius of metallic plates based on a novel finite region eigenfunction expansion (FREE) method," IEEE Sensors Journal, vol. 20, pp. 15099 - 15106, 2020. Doi: 10.1109/JSEN.2020.3009443.

53. R. Huang, M. Lu et al, "Measuring co-axial hole size of finite-size metallic disk based on a dual-constraint integration feature using multi-frequency eddy current testing," IEEE Transactions on Instrumentation and Measurement, vol. 70, pp. 1-7, 2020. Doi: 10.1109 /TIM.2020.3026762.

54. M. Lu et al, "Thickness Measurement of Metallic Film Based on a High-Frequency Feature of Triple-Coil Electromagnetic Eddy Current Sensor," IEEE Transactions on Instrumentation and Measurement, vol. 70, pp. 1-8, 2020. Doi: 10.1109/TIM.2020.3027929.

55. M. Lu et al, "Measuring Lift-Off Distance and Electromagnetic Property of Metal Using Dual-Frequency Linearity Feature," IEEE Transactions on Instrumentation and Measurement, vol. 70, pp. 1-9, 2020. Doi: 10.1109/TIM.2020.3029348.

56. M. Lu et al, "Lift-off tolerant pancake eddy-current sensor for the thickness and spacing measurement of non-magnetic plates," IEEE Transactions on Instrumentation and Measurement, early access, 2020. Doi: 10.1109/TIM.2020.3033377.

57. M. Lu et al, "Inversion of distance and magnetic permeability based on material-independent and lift-off insensitive algorithms using eddy current sensor," IEEE Transactions on Instrumentation and Measurement, early access, 2020. Doi: 10.1109/TIM.2020.3036099.

58. W. Yin et al, "Measurements of Thickness for Metallic Plates With Co-Axial Holes Using a Novel Analytical Method With the Modified Integration Range," IEEE Access, vol. 8, pp. 198301 - 198306, 2020.

59. X. Meng, M. Lu et al, "Inversion of lift-off distance and thickness for non-magnetic metal using eddy current testing," IEEE Transactions on Instrumentation and Measurement, vol. 70, 2020. Doi: 10.1109/TIM.2020.3038289.

60. M. Lu, X. Meng, et al, "Determination of surface crack orientation based on thin-skin regime using triple-coil drive-pickup eddycurrent sensor," IEEE Transactions on Instrumentation and Measurement, early access, 2020. Doi: 10.1109/TIM.2020.3044729.

61. Yin, W.; Tang, J.; Lu, M.; et al. An equivalent-effect phenomenon in eddy current non-destructive testing of thin structures. IEEE Access, 2019, 7, pp. 70296-70307.

62. Lu, M.; et al. Determination of Surface Crack Orientation Based on Thin-Skin Regime Using Triple-Coil Drive-Pickup EddyCurrent Sensor. IEEE Transactions on Instrumentation and Measurement, 2020, 70, pp. 1-9. DOI: 10.1109/TIM.2020.3044729

63. M. Lu, et al., "Prediction of the asymptotical magnetic polarization tensors for cylindrical samples using the boundary element method," In 2015 IEEE Sensors Applications Symposium (SAS), pp. 1-4. IEEE, 2015. 
64. R. Huang, M. Lu, A. Peyton, and W. Yin, "A novel perturbed matrix inversion based method for the acceleration of finite element analysis in crack-scanning eddy current NDT," IEEE Access, vol. 8, pp. 12438-12444, 2020.

65. J. Tang et al., "A Novel Efficient FEM Thin Shell Model for Bio-Impedance Analysis," Biosensors, vol. 10, no. 6, pp. 69, 2020.

66. L. Chen, et al., "Textile Based Capacitive Sensor for Physical Rehabilitation via Surface Topological Modification," ACS Nano, vol. 14, no. 7, pp. 8191-8201, 2020. DOI: 10.1021/acsnano.0c01643

67. Z. Jin, et al., "Methods of Controlling Lift-off in Conductivity Invariance Phenomenon for Eddy Current Testing," IEEE ACCESS, vol. 8, pp. 2169-3536, 2020. DOI: 10.1109/ACCESS.2020.3007216.

68. J. Tang, et al., "Effect of frozen-thaw injury on cell membrane and bio-impedance," In 2020 IEEE International Instrumentation and Measurement Technology Conference (I2MTC), pp. 1-6. IEEE, 2020.

69. J. Tang, et al., "Bio-impedance spectroscopy for frozen-thaw of bio-samples: Non-contact inductive measurement and finite element (FE) based cell modelling," Journal of Food Engineering, vol. 272, pp. 109784, 2020.

70. H. Xu et al., "Imaging a weld cross-section using a novel frequency feature in multi-frequency eddy current testing," InsightNon-Destructive Testing and Condition Monitoring, vol. 61, no. 12, pp. 738 - 743, 2019.

71. Y. Xie et al., "Novel Wearable Sensors for Biomechanical Movement Monitoring Based on Electromagnetic Sensing Techniques," IEEE Sensors Journal, vol. 20, no. 2, 2020. DOI: 10.1109/JSEN.2019.2943487

72. W. Yin et al., "Permeability invariance phenomenon and measurement of electrical conductivity for ferrite metallic plates," Insight-Non-Destructive Testing and Condition Monitoring, vol. 61, no. 8, pp. 472 - 479, 2019.

73. M. Lu et al., "A model for the triboelectric nanogenerator with inductive load and its energy boost potential," Nano Energy, vol. 63, pp. 103883, 2019.

74. M. Lu et al., "Forward solver for deep earth exploration and induction logging using custom built Edge-Element FEM technique," Acta Geologica Sinica, vol. 93, pp. 302-304, 2019.

75. L. Chen et al., "Whole System Design of Wearable Magnetic Induction Sensor for Physical Rehabilitation," Advanced Intelligent Systems, vol. 1, no. 1, pp. 1900037, 2019.

76. Y. X et al., "A self-powered radio frequency (RF) transmission system based on the combination of triboelectric nanogenerator (TENG) and piezoelectric element for disaster rescue/relief," Nano Energy, vol. 54, pp. 331-340, 2018.

77. W. Yin et al., "Custom edge-element FEM solver and its application to eddy-current simulation of realistic 2M-element human brain phantom," Bioelectromagnetics, vol. 39, no. 8, pp. 604-616, 2018.

78. L. Yin et al., "Detection of corrosion pits based on an analytically optimised eddy current sensor," Insight-Non-Destructive Testing and Condition Monitoring, vol. 60, no. 10, pp. 561-567, 2018.

79. W. Yin et al., "Acceleration of eddy current computation for scanning probes," Insight-Non-Destructive Testing and Condition Monitoring, vol. 60, no. 10, pp. 547-555, 2018.

80. W. Zhou et al., "Three-dimensional electromagnetic mixing models for dual-phase steel microstructures," Applied Sciences, vol. 8, no. 4, pp. 547-555, 2018.

81. M. Lu, et al., "Determining the magnetic permeability of ferrite steel strip by a custom inversion method," In Proc. 12th ECNDT, pp. 1-8. 2018.

82. J. Tang, et al., "Cellular structure analysis based on magnetic induction finite element method simulations and measurements," bioRxiv, pp. 275271, 2018. DOI: 10.1101/275271

83. J.R.S. Avila, et al., "A novel dual modality sensor with sensitivities to permittivity, conductivity, and permeability," IEEE Sensors Journal, vol. 18, no. 1, pp. 356-362, 2017.

84. T. Yang, et al., "Level measurement for saline with a small surface area using high frequency electromagnetic sensing technique," Measurement, vol. 101, pp. 118-125, 2017.

85. X. Meng, et al, "Evaluation of coating thickness using lift-off insensitivity of eddy current sensor," Sensors, vol. 21, no. 2, pp. $419,2021$.

86. Meng, X.; Lu, M.; Yin, W.; Bennecer, A.; Kirk, K.J. Evaluation of Coating Thickness Using Lift-Off Insensitivity of Eddy Current Sensor. Sensors 2021, 21, 419. https://doi.org/10.3390/s21020419

87. M. Lu, et al., "Thickness measurement of circular metallic film using single-frequency eddy current sensor," NDT \& E International, vol. 119, pp. 102420, 2021.

88. G. Hu, et al., "Measurement of Radius of a Metallic Ball Using Eddy Current Testing Based on Peak Frequency Difference Feature," Measurement, vol. 184, pp. 109876, 2021.

89. Y. Xie, et al., " A novel design of window function modulated meander-line-coils EMATs for unidirectional Rayleigh waves generation and sidelobes suppression," NDT \& E International, vol. 123, pp. 102501, 2021.

90. M. Lu, et al., "Lift-off invariant inductance of steels in multi-frequency eddy-current testing." NDT \& E International, vol. 121, p. $102458,2021$.

91. Z. Jin, et al., "Boundary-element analysis of magnetic polarization tensor for metallic cylinder." IEEE Access, vol. 9, pp. 6325063256,2021 